\title{
SOBRE LA REORGANIZACIÓN DEL SEÑORÍO RURAL Y LA FIGURA DEL BAIULUS EN LA CATALUNYA DEL NORESTE DE LOS SIGLOS XII Y XIII ${ }^{1}$
}

\author{
VÍCTOR FARÍAS ZURITA \\ Universitat Pompeu Fabra \\ (Barcelona $)^{2}$
}

\begin{abstract}
SUMARIO
1. Los baiuli. 1.1. Las funciones. 1.2. los auxiliares. 1.3. El ámbito de actuación.- 2. La baiulia.- 3. La retribución del baiulus.- 4. El estatus de los baiuli. 4.1. El estatus socio-jurídico. 4.2. Las distinciones.
\end{abstract}

\footnotetext{
${ }^{1}$ Abreviaturas. Diccionarios. DECLC (J. COROMINES, Diccionari etimològic i complementari de la Llengua catalana, Barcelona 1980-1991). GMLC (M. BASSOLS/J. BASTARDAS..., Glossarium Mediae Latinitatis Cataloniae. Voces latinas y romances documentadas en fuentes catalanas del año 800 al 1100, Barcelona 1962...). Fuentes inéditas. ACA (Arxiu de la Corona d'Aragó): C (Cancilleria), OR (Ordes Religioses), P (Patrimonials). ACB (Arxiu Capitular de Barcelona), Lib. Ant. (Libri Antiquitatum), Perg. Div. (Pergamins Diversorum). ACG (Arxiu Capitular de Girona). ADG (Arxiu Diocesà de Girona). AHG (Arxiu Històric de Girona). AHT (Arxiu Històric de Terrassa). AMM (Arxiu del Monestir de Montserrat). ASPP (Arxiu de St. Pere de les Puelles). MASMM (Museu Arxiu de Sta. Maria de Mataró). Fuentes editadas. ASA (J. Alturo i PeruCho, L'arxiu antic de Sta. Anna de Barcelona, Barcelona, 1985). CCM (J. M. MARQUÈS, Cartoral dit de Carlemany, Barcelona, 1993). CDSG (R. MARTí, Col-lecció diplomàtica de la Seu de Girona (817-1100), Barcelona, 1997). CDSDG (J. M. MARQUĖS, Col-lecció diplomàtica de Sant Daniel de Girona (924-1300), Barcelona, 1997). CSCV (J. RIUS SERrA, Cartulario de 'St. Cugat del Vallés', Barcelona, 1946-1947, Madrid, 1981). CPBA (P. PUIG I USTRELL, Capbreu primer de Bertran acòlit, notari de Terrassa, 1237-1242, Barcelona, 1992). CSMR (J. M. MARQUĖS, El cartoral de Sta. Maria de Roses (segles X-XIII), Barcelona, 1986). DB (L. G. ConstanS, Diplomatari de Banyoles, Banyoles, 1985-1993). DJA (A. HUICI Miranda/M. D. CABANES PeCourt, Documentos de Jaime I de Aragón, València/Zaragoza, 1976...). DSMA (E. PRUENCA/J. M. MARQUĖS, Diplomatari de Santa Maria d'Amer, Barcelona, 1995). DSPM (J. M. PONS I GuRI, Diplomatari del monestir de Sant Pol de Mar, en J. M. PONS I GURI, Recull d'estudis d'història jurídica catalana, Barcelona, 1989, 3, pp. 363-411)

${ }^{2}$ Esta contribución es un resultado de las investigaciones llevadas a cabo en el marco del proyecto Los 'masos' y su 'vila' en la Cataluña noriental de los siglos XIII y XIV: estudio de un espacio local integrado a traves de las fuentes notariales, financiado por el Ministerio de Cultura y Educación (DGESIC PB 98-0454).

"Anuario de Estudios Medievales", 30/2 (2000)
} 
El siglo XII ha de considerarse como una época en la que el señorío rural experimentó en el noreste de la Catalunya Vella cambios que determinarían de manera decisiva su fisonomía hasta la época moderna. Esto se refiere, al menos, a uno de sus componentes esenciales: el mas (mansus), que a partir de mediados de dicho siglo pasó a constituirse como la unidad básica tanto de la apropiación señorial como de la explotación campesina. Esta constitución de una unidad de explotación y apropiación, estable y bien equipada, estuvo acompañada, por otra parte, por una reorganización de los grandes dominios que se habían configurado en los siglos IX-XI. Estos dominios no eran en su origen sino unos conglomerados hetereogéneos de bienes concentrados en áreas geográficas determinadas (en torno a un monasterio benedictino, por ejemplo). Los mismos aparecen como una mezcla de parcelas cultivadas (terras, vineas), espacios incultos (silvas, garrigas, pascua), instalaciones (molendinos) y edificaciones (casas, domos). La reorganización de estos dominios heterogéneos a mediados del siglo XII se presenta como la creación sistemática y a gran escala de masos dispersos a partir de los antiguos elementos que componían a aquellos. De esta manera, los dominios de finales del siglo XII y del siglo XIII (detalladamente documentados gracias a los capbreus que mandaron redactar los señores) pasaron a presentarse como un gran agregado de masos, como una scattered seigneury ${ }^{3}$, sostenida por un notable incremento del número y una diversificación del tipo de réditos que gravaban de forma individualizada a cada mas y a sus ocupantes.

\section{LOS BAIULI}

La gestión de los múltiples masos y de los restantes componentes de un dominio laico o eclesiástico requirió desde muy pronto el reclutamiento de unos agentes especializados cuya tarea sería la de encargarse específicamente y en representación de su señor de la gestión de dicho dominio ${ }^{4}$. Para

${ }^{3}$ P. Freedman, The Origins of Peasant Servitude in Medieval Catalonia, Cambridge..., 1991, pp. 31-38.

${ }^{4}$ Para estos agentes $c f$. J. BRUTAILS, Etude sur la condition des populations rurales en Roussillon au Moyen Age, París, 1891, pp. 232-239; E. DE HINOJOSA, El regimen señorial y la cuestión agraria en Cataluña durante la Edad Media, Madrid, 1905, pp. 128-133. J. LALINDE ABADÍA, La jurisdicción real inferior en Cataluña ('corts, veguers, batlles'), Barcelona, 1966, pp. 56-68 y $237-258$. 
designar estos agentes se recurrió al término baiulus (batle, pl. batles $>$ cat. batlle) $)^{5}$. Como sinónimo de baiulus se empleó hasta mediados del XII, aunque raramente, el término arcaizante villicus ${ }^{6}$. Otros sinónimos eran quizas minister y ministrale ${ }^{7}$. El saio, por su parte, parece haber sido un auxiliar del baiulus $^{8}$. Los primeros baiuli nos constan para la segunda mitad del siglo XI y las referencias aumentan para la primera mitad del siglo XII. Pero, las noticias de baiuli en las fuentes se disparan para la segunda mitad del mismo siglo, hecho que nos permite fechar entre 1150 y 1200 la difusión definitiva del cargo de baiulus. La misma resulta, por lo tanto, paralela a la difusión del mas y a la reorganización de los dominios.

En los apartados que siguen estudiaremos las funciones y los ámbitos de actuación que se atribuyeron a los baiuli y la manera en que eran retribuídos. A continuación, presentaremos lo que era la baiulia en tanto que cargo (officium), para acabar precisando el estatus social, jurídico y político de los baiuli. El conjunto de estos apartados, que deben mucho a estudios previos como los de E. de Hinojosa, J. Brutails, J. Lalinde Abadía, P. Bonnassie y Th. N. Bisson, está basado en una revisión exhaustiva de la información que, para el noreste de la Catalunya Vella de los siglos XII y

${ }^{5}$ Sobre el término baiulus $c f$. GMLC, cols. 223-226; E. RODÓN BINUÉ, El lenguaje técnico del feudalismo en el siglo XI en Cataluña. Contribución al estudio del latín medieval, Barcelona, 1957, pp. 36-38. El término designa en un principio a un «tutor de menores» y a un «señor feudal que ejerce su protección o tutela sobre determinadas personas o, lo que es más frecuente, sobre lugares»; $c f$. RODÓN BINUÉ, loc. cit. Desde la segunda mitad del siglo XI se aplica cada vez más frecuentemente a individuos a los que se atribuían funciones de gestión en el marco de un dominio. Para el cat. batlle, fem. batllessa, cf. DECLC, 1, cols. 727-728.

${ }^{6}$ Para referencias a un villicus cf. AHT, Perg. I, 109 (1117); ACB, Perg. Div. 1.1, 350 (a) (1128); Bernat Cuc, baiulus de la catedral en Vilanova del Vallès, era designado en 1156 como baiulus y en 1157 como villicus, cf. ACB, Lib. Ant. III 60 (1156); ACB, Lib. Ant., III 69 (1157); hasta 1192 sería denominado siempre baiulus. El término villicus es un préstamo del bajo latín; $c f$. IsIDORO DE SEVILla, Etimologias, ed. J. OROZ RETA; M.-A. MARCOS CASQUERO, Madrid, 1993, IX, 4, 33: «vilicus proprie villae gubernator est».

${ }^{7} \mathrm{El}$ término ministrale, ministralo aparece ya en la primera mitad del siglo XI, cf. AHT, Perg. I, 34 (1035-36); AMM, Perg. St. Llorenç del Munt, 17 (1039); ACA/OR, Perg. St. Llorenç del Munt, 192 (1065); aunque se emplea raramente en el siglo XII; $c f$. ACB, Lib. Ant., IV, 203 (1167), que trae minister como sinónimo de ministrale; DSPM, 16 (1063): ministrum et baiulum.

${ }^{8} \mathrm{El}$ término saio designaba hasta mediados del siglo XI un agente judicial, auxiliar del iudex, cf. RODÓN BINUÉ, Lenguaje, p. 229; P. BONNASSIE, La Catalogne du milieu du Xe a la fin du XIe siècle. Croissance et mutations d'une société, Toulouse, 1975-1976, 1, p. 192. (Allí mismo también noticias sobre los precedentes visigodos). Posteriormente parece convertirse en un agente señorial, dependiente del baiulus, $c f$. infra y BRUTAILS, Etude, p. 239. 
XIII, proporcionan los documentos en pergamino, los registros notariales y algunos capbreus.

\subsection{Las funciones}

Siguiendo a P. Bonnassie puede afirmarse que la función del baiulus era la de actuar «a la fois comme représentant personnel du seigneur et comme le responsable de l'exploitation économique de la seigneurie»" En este sentido pueden documentarse baiuli que se encargaban de la construcción de nuevos masos $^{10}$, que proporcionaban albergue a su señor... ${ }^{11}$ Sin embargo, el peso de la gestión del baiulus se dirigía a tres ámbitos muy precisos:

1) La administración del dominio propiamente dicha. El baiulus intervenía (tenens locum domini) en las transacciones realizadas por su señor; supervisaba las transmisiones y transacciones realizadas entre los tenentes del dominio; sancionaba y aprobaba (consilio et assensu) los contratos con su signum $^{12}$; recibía las encomendaciones de los homines proprios ${ }^{13}$, de la misma manera que otorgaba y signaba las redemptiones hominum et mulierum ${ }^{14}$; concedía las remissiones statice ${ }^{15}$; y defendía y asistía en las disputas

${ }^{9}$ Bonnassie, Catalogne, 2, pp. 597-598; LALINDE ABAdíA, Jurisdicción, pp. 237-258.

${ }^{10}$ ACA/OR, Perg. St. Llorenç del Munt, 290 bis (1154): los monjes de St. Llorenç del Munt ceden a Pere Guerau y su esposa Maiasenda un honor y la baiulia de Sentmenat. A esta concesión se añade la clausula siguiente: «si volueritis hedificare ... mansos ubi stent homines in pretaxata tenedone, de unoquoque manso reddatis nobis per unumquemque anno I par caponum. Aliud quoque censum et servicium fiat vestrum solidum et liberum».

"ACB, Lib. Ant., IV, 504 (1211): «Sinfredus de Valle Loparia est baiulus canonice et donat albergam preposito». ACA/OR, Rotllos St. Miquel de Cruilles, 15/1 (1243): «pro quam baiulia dabis nobis ... annuatim unam albergam». ACA/OR, Perg. St. Llorenç del Munt, 408 (d) (1246): "teneas nobis in manso de Ameniis hospicium preparatum vinendo ibi de bonibus nostris". ACA/OR, Rotllos St. Miquel de Cruilles, 19/2 (1290): «annuatim albergam de tribus equitantibus cum tribus troteriis et cocho et porchum de duobus solidos monete de quaterno vel II solidos".

${ }^{12} C f$., por ejemplo, ACA/OR, Rotllos St. Pere de Galligants, 29/26 (1228); 47/3 (1240); 41/10 (1275); $41 / 55$ (1289); $37 / 5$ (1299).

${ }^{13}$ ACA/C, Perg. Jaume I, 2135 (1272); AHG, Notarials Amer, Reg. 5, fol. 18 (1290).

${ }^{14}$ AHG, Notarials Castelló d'Empúries, Reg. 3, III idus ianuarii (1288); V kalendas iulii (1288); AHG, Notarials Amer, Reg. 5, fol. 68 (1291); AHG, Notarials Castelló d'Empúries, Reg. 12, kalendas decembris (1299).

${ }^{15}$ ACA/OR, Perg. St. Cugat del Vallès, 1858 (1295). 
judiciales a su señor ${ }^{16}$. Además le correspondía vigilar el trabajo sobre las laborationes gestionadas directamente por el señor ${ }^{17}$.

Sin embargo, la tarea administrativa más relevante del baiulus era la de recaudar las exigencias del señor («levare expletos», «recolligere eximenta et expleta», «congregare fructos et expletos et redditus et proventus») ${ }^{18}$. Ello lo realizaba apoyado en inventarios (breves, caput brevia > cat. capbreus) que él mismo se habría encargado de hacer redactar ${ }^{19}$. Esta tarea resultaba tanto más necesaria por la importancia que habían adquirido desde el siglo XII $\mathrm{y}$ en el conjunto de los ingresos señoriales las imposiciones alíquotas (agraria), cuyo monto real resultaba siempre difícil de verificar y que debieron propiciar más de un intento de fraude por parte de los homines del señor $^{20}$. La presencia personal del baiulus era obligada en el momento de la cosecha (tempore messium), cuando se segaba y se trillaba sobre la era el cereal (ad seccare, batre, triturandum $)^{21}$, momento en el que se recaudaban

${ }^{16} \mathrm{ACA} / \mathrm{OR}$, Perg. Montalegre, 417 (1257).

${ }^{17}$ ADG, Perg. Mitra, 15, 63 (1173): «faciat ipsos blads exarcolare, colligere et resecare et terere hominibus episcopi cum cibo ipsius episcopi donec in granarium congregentur». AHG Notarials Amer, Reg. 7, fol. 20 (1292): «facias fieri hominibus nostris vel aliis laboracionem nostram, tam vineas quam terras, quas habemus apud Columbarium de omnibus laboracionibus cum nostris sumptibus tamen».

${ }^{18}$ ACB, Lib. Ant. IV, 223 (1135); ACB, Perg. Div. 1.5, 376 (1198); ACA/C, Perg. Alfons I, 647 (1193); ACA/P, Sentmenat, 16, P, 14 (1213); $C P B A, 1108$ (1241); ACA/OR, Perg. St. Llorenç del Munt, 408 (1226).

${ }^{19} \mathrm{ACB}$, Lib. Ant., IV, 461 (sin fecha); CDSDG, 59 (1169): un antiguo baiulus del monasterio de St. Daniel de Girona aparece como responsable de establecer una «commemoratio honoris Sci. Danielis quem habet in villa et infra terminos de Saltu, de suis molendinis scilicet et de ortis, de mansis cum suis tenedonibus et de censu et usatico". Para el fisco real de Llagostera se ha conservado un «sacramentale fidelitatis quod probi homines Locustarie sub vinculo sacramenti fecerunt sub manu et in presencia Berengarii de Colle et Berengarii de Columbario, baiulus eiusdem ville, de omnibus eximentis et directis atque antiquis usaticis que dominus comes et dominus rex, filius eius, soliti erant habere et recipere in omni parroechia Locustarie»; Th BIsson, Fiscal Accounts of Catalonia under the Early Count-Kings, 1151-1213, Berkeley/Los Angeles, 1983, 2, doc. 101 ([...1185-1196]).

${ }^{20} \mathrm{Ll}$. TO FIGUERAS, Le mas catalan du XII siècle: genèse et évolution d'une structure d'encadrement et d'asservissement de la paysannerie, "Cahiers de Civilisation Medieval", 36 (1993), p. 165.

${ }^{21}$ ACB, Perg. Prepositura Gener, 27, 335 (1143): «tempore messium ad seccare et ad batre ipsum blad nos ibi habeamus nostrum baiulum aut alium nostrum nuncium quod accipiat nostrum directum»; DSPM, 36 (1161): se cede un campum a cambio de quartum y braciaticum y usaticos con la condición «tu non metatis supradictum campum sine nostro baiulo vel nostro nuncio et ne teratis nichil in eodem campo absque nostra licencia»; ADG, Perg. Pia Almoina, Fornells, 13 (1170): el señor exige que los eximenta de un mas «non dividantur nec leventur sine nostro baiulo»; ACA/OR, Perg. St. Marçal del Montseny, 756 (1209): «homines de dicta Yslela non levent espleta de dicta honore de qua donent tascha donec denuncient baiulis prioris Sci. Marciali 
los agraria, los censos, las decimas y las primicias. En 1198, por ejemplo, los monjes de la abadía de St. Cugat del Vallès encomendaron a Arnau de Noguera y a su madre, Arnalleta, en vida la baiulia de Palautordera, en el Vallès, «ut habeatis eam et recolligatis omnia eximenta et espleta quod inde nobis pervenire debent et liberetis nobis fideliter salvo vestro redecimo quod abebatis ad fidelitatem et servicium nostrum $»^{22}$. Las diversas obligaciones de un baiulus vienen también descritas en una charta de 1239 por la cual Guigó, prior de Sta. Maria de Terrassa, cedió a Berenguer de Vilar de forma vitalicia la baiulia de las primicias que el priorato agustiniano exigía en el término de Terrassa. Berenguer recaudaría personalmente el cereal y el vino, con la ayuda de una bestia de carga, y, dado el caso, bajo la supervisión de un nuncius del priorato ${ }^{23}$. El baiulus debía encargarse de llevar y depositar las cosechas recaudadas a una domus del priorato. El baiulus recibiría, al margen de su remuneración (retrodecimum), anualmente seis quarters de cebada para su alimento y cinco quarters de espelta para su bestia, además de una somada de vino por cada jornada de trabajo ${ }^{24}$. Si el baiulus enfermaba durante el período de las cosechas, estaba obligado a proporcionar un sustituto idóneo, previo consentimiento del priorato $0^{25}$.

En algún caso el señor podía prometer al baiulus ciertas facilidades durante su trabajo y en el ejercicio de sus funciones. Así, en 1226, el abad del monasterio benedictino de St. Llorenç del Munt concedía a su baiulus de Matadepera, en el Vallès, que «dum eximenta baiulie istius levabis et eciam dum negocium nostrum in aliquo loco feceris, explebas et comedas de bonis

vel baiulo capellani Sci. Iuliani. Et cum illo baiulo qui ibi fuerit, levent dicta espleta». Para la prohibición de triturare sin la licentia y sin el nuntio del señor $c f$. ACA/OR, Perg. St. Cugat del Vallès, 1192 (1250).

${ }^{22}$ ACB, Perg. Div. 1.5, 376.

${ }^{23} C P B A, 689$ : «dono ... tantum in vita tua baiuliam nostram primiciarum Terracie, videlicet bladi et convivus bladi et vindemie, tali modo, quod tu ipsas primicias bladi et vini et dicta convivia bladi fideliter congreges et leves in tua propria persona et cum tua bestia et cum nuncio nostro insimul si nos ipsum mitere voluerimus. Et si mitere nuncium noluerimus, mitas et habeas tu ibi dictum nuncium et comendat in domo nostra cum dictas primicias levaveris. Et omnes dictas primicias et convivia in domo nostra mitas. De quibus omnibus tu recipias et habeas tuum retrodecimum pro tuo labore».

${ }^{24}{ }^{4} \mathrm{Et}$ habeas quolibet anno in messis pro tua bestia VI quartarias et mediam ordei pro cibaria et in vindemiis $\mathrm{V}$ quartarias de spelta pro cibaria bestie et quoque die negociaturo unam somadam vindemie».

${ }^{25}{ } \mathrm{E}$ t si forte tibi infirmitas in tempore messium et vindemiarum evenerit, mitas ibi unum bonum nuncium cum nostro consilio". 
domus nostre». Además, le prometía que «in tempore vero messium acomodemus nos in colligenda eximenta baiulie duos sachos et unam bonam bestiam ${ }^{26}$. En 1292 el abad de Sta. Maria d'Amer prometía a su baiulus de Colomers «dare ad comedendum quocienscumque nos erimus apud Columbarium scilicet pro persone tue tamen»; además le concedía «quod possis stare in hospicio nostro de Columbariis cum tua familia et tenere ibi bona tua quamdiu tenebis dictas baiulias ${ }^{27}$.

2) La explotación del mandamentum y districtum. Al baiulus correspondía asimismo hacer efectivas todas aquellas exigencias que el dominus podía recaudar en virtud de su facultad de mandare y distringere. Entre éstas cabe incluir todas aquellas exactiones arbitrarias, como las questias, toltas y forcias, cuya recaudación material correspondió al agente señorial. Asimismo correspondió al baiulus la recaudación del locidum, la imposición que gravaba el servicio de la herrería (fabrica) señoria ${ }^{28}$.

3) El ejercicio de la justicia. El baiulus podía ejercer en lugar del dominus la facultad de juzgar, castigar y multar que éste había impuesto sobre los homines y feminas de su dominio. Como agente judicial aparece el baiulus en 1205 en una charta por la cual el obispo de Barcelona exigió a su vasallo Bernat, del castillo de Castellbisbal, que «placita nec iusticiam nec stabilimentum facere nec accipere debetur in dicto castro sine eius baiulo» ${ }^{29}$. La facultad judicial del baiulus se refería a infracciones ciertamente diversas. Así, a un baiulus del monasterio de St. Llorenç del Munt se le reconoció la capacidad de distringere y pignorare los homines que se negasen a hacer efectivas las imposiciones que debían a su señor ${ }^{30}$. En 1213, por otra parte, el abad del monasterio de St. Cugat cedió a Bernat, baiulus de Palau de Plegamans, en el Vallès, tres masos del dominio de Plegamans, atribuyéndole la facultad de sancionar toda corporalem iniuriam que cometiesen sus ocupantes contra los monjes o su familia. Cualquier pleito entre los ocupantes de estos tres masos y el resto de los tenentes del dominio sería derrimido ante un preboste del

\footnotetext{
${ }^{26}$ ACA/OR, Perg. St. Llorenç del Munt, 408 (a).

${ }^{27}$ AHG, Notarials Amer, Reg. 7, fol. 20.

${ }^{28}$ ACA/C, Perg. Alfons I, 16 (1164).

${ }^{29}$ ACB, Lib. Ant., IV, 190 (1205).

${ }^{30} \mathrm{ACA} / \mathrm{P}$, Sentmenat, 20, D, 25 (1163): «si illi homines nolue < rint $>$ dare prescriptas pernas vel capons sive ... taschas, distringat (scil. baiulus) illos bene atque pignoret».
} 
monasterio, aunque previa obligación de firmare directum ante el baiulus ${ }^{31}$. En 1293, por último, un baiulus del monasterio de St. Esteve de Banyoles hubo de prometer al abad «quod servem iusticiam inter homines baiulie mee quos ego debeo distringere pro posse meo». Este correcto ejercicio de la justicia tenía también el fin de evitar «quod per culpam meam ad aliam curiam non apportebit eos habere recursum ${ }^{32}$.

El poder de mando que, de esta manera, se concedió al baiulus como gestor del districtum señorial hizo de él la instancia idónea para vigilar la convivencia pacífica de los hombres sometidos a un mismo señor. Cuando en 1296 el arcediano de La Selva ỳ preboste de Aro y la domina de St. Sadurní concedieron a los habitantes de la villa y parrochia de St. Sadurní de l'Heura, en el Baix Empordà, una serie de éstatutos sobre materias diversas, encargaron a su baiulus (y al saio) hacer observar («distringere et facere in omnibus observari») dichos estatutos y sancionar (mediante multas y castigos corporales) las infracciones a los mismos. De esta manera, se le atribuyó al baiulus la facultad de juzgar tanto al que entraba sin autorización en los hortos y trileas ajenos y al que cazaba «cỏlựmbos cum aliquo ingenio», como al que «extraxerit gladium intus villam seu parrochiam» y al que «moverit rixam intus villam seu parrochiam». En el caso de amenaza exterior, el baiulus quedaba además responsabilizado de hacer observar y organizar el sonum cornu que convocaba en armas a los hảbitantes de St. Sadurnî3.

\subsection{Los auxiliares}

En sus cometidos el baiulus podía disponer de agentes auxiliares. Entre éstos se cuentan los saiones. La existencia de estos auxiliares nos viene documentada en 1151 para los fisci de Prats de Molló, en el Vallespir, donde la gestión del baiulus condal era apoyada por tres saig ${ }^{34}$. Los saiones eran

\footnotetext{
${ }^{31} \mathrm{ACA} / \mathrm{P}$, Sentmenat, $16, \mathrm{P}, 14$ (1213): «et si corporalem iniuriam homines eorundem trium mansorum abbati vel preposito vel eius familie intulerunt, firment eis directum et respondeant sub examine suo. Et si ipsi homines et alii ipsius baiulie damnum inter se iuribus vel in corpore dederint, firment directum Bernardo et placitent sub examine prepositi».

${ }^{32} \mathrm{DB}, 432$.

${ }^{33}$ ADG, Perg. Mitra, 17, 1 (1296) (J.M. MARQUÈs, La senyoria eclesiàstica de St. Sadurní de l'Heurà, fins al 1319, "Estudis del Baix Empordà", 3 (1989), ap. 17).

${ }^{34}$ Bisson, Accounts, 2, doc. 1, L.
} 
agentes vinculados por fidelidad tanto al baiulus como al señor ${ }^{35}$. Los mismos eran instituídos por el baiulus en su saionia y el mismo les otorgaba (durante un tiempo limitado) funciones muy concretas: la recaudación de los censos en moneda de un señorío, por ejemplo ${ }^{36}$. Al parecer el baiulus era también el encargado de la remuneración del saio $^{37}$.

En tanto que responsable de la administración de la justicia local, podía, por otra parte, otorgarse al baiulus la facultad de instituir a los oficiales que llevarían cotidianamente esta administración («ponere et constituere iudicem, sayones, banderios et alios officiales») ${ }^{38}$. Entre los otros oficiales que auxiliaban al baiulus, concretamente en las tareas administrativas necesarias para mantener en marcha el dominio, podemos citar el forestarius (el encargado de vigilar los espacios incultos del señor), el porcarius (el encargado de las piaras), el pastor (el encargado de los rebaños), el monerius (el encargado de los molinos) y el ferrarius (el encargado de la herrería). Todos ellos se hallaban, en mayor o menor medida, sometidos a la autoridad del baiulus como máximo representante del señor.

\subsection{El ámbito de actuación}

El ámbito de actuación de un baiulus era variable. De hecho, el término baiulia sólo llegó a designar en casos muy concretos un distrito con límites definidos. Por lo demás, la baiulia se concebía como un ámbito geográfico variable y que podía referirse tanto a una villa y su entorno como a una parroquia o a un conjunto de parroquias. Según una charta de 1204 Deodat de Terradis, un baiulus del capítulo de Girona ejercería su cargo en las parroquias de St. Julià de Corts, St. Andreu de Mata, St. Joan de

${ }^{35} C C M, 312(1166)$.

${ }^{36} C P B A, 52$ (1237): un saionus recibe la saioniam totius castri Terracie y promete a los baiuli regis de Terrassa «esse ipsis fidelis saionus legalis et directus in omnibus usque ad festum Sce. Crucis madii et levare et congregare omnes denarios census Terracie et dare et solvere incontinenti eis et aliis senioribus sicut est consuetum per alios annos et per alios saiones condam transactos, levatis pallicis certis». AHG, Notarials Amer, Reg. 4, fol. 128 v. (1286): «Graianus baiulus de Rupito, pro nobili domino Raimundo Fulchoni, dono et concedo ac comendo tibi Berengario de Campis, de Sca. Columba, totam sayoniam parrochie Sce. Columbe et tocius termini castri de Farneriis et que sis inde fidelis et recipio a te XL solidos de terno».

${ }^{37} \mathrm{~B} .-\mathrm{J}$. ALART, Documents sur la langue catalane des anciens comtés de Roussillon et de Cerdagne, París, 1881, p. 29: en 1068 un baiulus retribuye a su saio con una eminam vini.

${ }^{38}$ AHG, Notarials Castelló d'Empúries, Reg. 1, fol. 34 (1279). 
Borgonyà del Terri, St. Esteve de Sords y Sta. Eulàlia de Pujals dels Cavallers $^{39}$. En 1246 Pere Carraria recibió de la abadesa de St. Daniel la baiuliam de los honores del monasterio en las parroquias de St. Esteve de Vilafreser, Sta. Eulàlia de Pujals, Santa Llogaia, St. Martí de Fellines y St. Vicenç de Viladasens ${ }^{40}$. En $1292 \mathrm{el}$ abad de Sta. Maria d'Amer, por su parte, otorgaba a Pere Marchesii, «omnibus diebus vite tue tantum, totam illam nostram baiuliam de Tornavelle», la cual incluía las parroquias de Sta. Maria de Ginestar, St. Gregori, St. Feliu de Cartellà, St. Vicenç de Canet d'Adrí, St. Llorenç d'Adrí, St. Joan de Montbó, St. Martí de la Mota, St. Medir y St. Martí de Riudellots de la $\mathrm{Creu}^{41}$.

La baiulia, sin embargo, que en 1256 cedió Beatriu de Medinyà, la domina de Toralles, a Guillem de Pomerio se refería a «tocius mei honoris culti et heremi et omnium tenedonum et possessionum que et quas habeo ... in tota parrochia Sci. Martini de Toraliis et eius terminis et pertinenciis ${ }^{42}$. En 1198 Arnau de Nogera y su madre Arnalleta recibieron de St. Cugat la «baiuliam totam integriter Palaci de Vitamenia» ${ }^{43}$. En 1241 el monasterio de Amer cedió a un baiulus la gestión de aquellos «honores quos habemus a cruce de Lorano usque ad pontem Gerunde», con el fin «ut bene et fideliter ... omnia congreges et nobis reddas» ${ }^{44}$. En 1246 el abad de St. Llorenç del Munt ecomendó a Guillema de Ameniis en vida la «baiuliam mayorem nostram de Mata de Pera» para que «congreguetis ipsos fructus et redditus ab eo loco qui vocatur de Portela in sursum quocumque loco nos voluerimus» ${ }^{45}$.

Las variaciones en lo que se refiere al ámbito de actuación de un baiulus se explican, sin duda, por las diferencias en la densidad de las respectivas posesiones a gestionar. En este sentido, puede pensarse que dicho ámbito sería tanto más amplio cuanto más dispersos estuvieran y menos numerosos fueran los masos que se encomendaban a un baiulus. Añadámos,

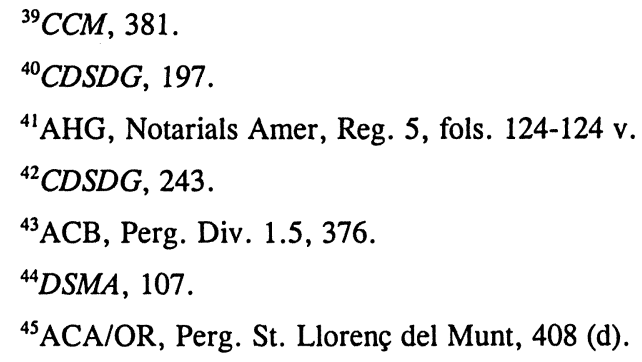


por último, que la atribución de un ámbito de actuación determinado podía vincularse a la tarea de recaudar réditos muy específicos, como los diezmos y las primicias. Así, en 1239 el prior agustiniano de Sta. Maria de Terrassa cedió a Berenguer de Vilar la «baiuliam nostram primiciarum Terracie, videlicet bladi et convivus bladi et vindemie». ${ }^{46} \mathrm{Y}$ en 1258 el prior de St. Miquel de Cruïlles encargó a Guillem Figeria, en el entorno de Cruïlles, «totam nostram baiuliam tocius decime et primiciarum» ${ }^{47}$.

\section{LA BAIULIA}

La baiulia (baiolia, bagulia, baglia, batlia, badlia, pl. batlies) o el baiulivium era el cargo ejercido en representación del dominus: el officium baiulie $^{48}$. La misma era otorgada (comendare) por el señor mediante una charta (instrumentum) al futuro baiulus ${ }^{49}$. Éste la detendría generalmente in perpetuum (aunque no son raras las concesiones vitalicias, sobre todo a partir del siglo XIII) ${ }^{50}$. La cesión implicó desde el siglo XII el pago de determinadas $\mathrm{y}$ variables sumas en concepto de intrata (pro acapite, pro donacione et stabilimento) y/o laudemium $^{51}$. La relación que se establecía mediante esta

${ }^{46} C P B A, 689$.

${ }^{47}$ ACA/OR, Rotllos St. Miquel de Cruilles, 13/3.

${ }^{48}$ Sobre el término baiulia cf. GMLC, cols. 216-223; RODÓN BINUÉ, Lenguaje, pp. 33-36. Para el cat. batllia y batlliu cf. DECLC, 1, cols. 627-728.

${ }^{49} \mathrm{La}$ ausencia de una tal charta daba al señor la posibilidad de exigir la restitución de la baiulia, cf. ACA/OR, Perg. St. Llorenc del Munt, 422 (1231): el abad de St. Llorenç del Munt exige a Ferrer de Sobarbar la baiulia que éste detenía «ratione comande que fuit facta patri dicti Ferrarii sine titulo et laudacione dicti cenobii Sci. Laurencii». El baiulus responde «quod predicta baiulia tenebat per predictum cenobium per longam prescriptionem ipse et pater suus cum titulo et laudatione dicti cenobii set titulum erat amissum». La sentencia del iudex es favorable al abad.

${ }^{50}$ Para concesiones vitalícias $c f$. ACA/OR, Perg. St. Llorenç del Munt, 408 (a) (1226); $C P B A, 1108$ (1241); ACA/OR, Perg. St. Llorenç del Munt, 408 (d) (1246); CDSDG, 243 (1256); AHG, Notarials Amer, Reg. 5, fols. 124-124 v. (1291); Reg. 7, fol. 20 (1292); fols. 32 v.-33 (1293); 34 v.-35 (1293).

${ }^{51}$ Para ejemplos $c f$. ACA/OR, Fons St. Joan de Jerusalem, Armari 16, Plec 15/17/c (1193): el baiulus paga cien solidos por la baiulia de Cassà que le ha sido otorgada por el vizconde de Cabrera. MASMM, Perg. Marfâ, 1 (1182): Estefania y su marido Guillem de Turre y su hijo perciben 50 sous de Barcelona de Joan de Valle Maiori por la cesión de un mas «in termino castri Matharonis» y la «baiuliam totius nostri honoris quem in iamdicto termino habemus». ACB Perg. Pia Almoina, 4, 101, 28 (b) (1210): Guillem de Campsentelles y su esposa Agnès confirman a Arnau el mas heredado de sus padres y le ceden la «baiuliam nostram, dominium nostrarum rerum totius honoris nostri quem habemus et habere debemus in termino castri de Matarone», todo a 
cesión constituía al baiulus como sujeto vinculado de manera estrecha y precisa a su señor. De entrada, la comendatio baiulie se acompañaba de un juramento de fidelidad por parte del baiulus ${ }^{52}$, al cual el señor exigía invariablemente que «sis mihi bonus, fidelis et legalis» («sicut baiulus debet esse domino suo») $)^{53}$, y que ejercería «bene, utiliter, fideliter et legaliter» el officium baiulie ${ }^{54}$, y que «bene proteges et custodias et cures omnia nostra iura et dominacione ${ }^{55}$. La fidelidad exigida por el señor se extendía al rendimiento de cuentas: así, en 1220 el monasterio de St. Llorenç del Munt decidió establecer para la correcta gestión de sus dominios «quod omnes baiuli teneantur iuramento abbati et preposito reddere rationem de omnibus exitibus et redditibus sue baiulie». ${ }^{56} \mathrm{Y}$ en $1292 \mathrm{el}$ abad de Amer hacia prometer a su baiulus de la baiulia de Tornavelle que «computes annuatim nobiscum vel cum successoribus nostris de dicta baiulia» ${ }^{57}$.

Desde finales del siglo XII el vínculo con el señor acostumbra a hacerse más estrecho: el señor exigía al baiulus y a su descendencia ser su solidus homo ac habitantes, su homo proprius ${ }^{58}$. La asunción del cargo se condicionaba a la prestación de un homenaje («hominaticum cum iunctis manibus hosculando») y a que el futuro baiulus se hubiera redimido de un

cambio de diez sous de Barcelona. ACA/OR, Perg. St. Llorenc del Munt, 408 (a) (1226): un baiulus paga a los monjes de St. Llorenç del Munt 360 sous de Barcelona por la baiulia de Matadepera. ACA/OR, Perg. St. Llorenç del Munt, 408 (d) (1246): Guillema de Ameniis paga setenta sous por haber recibido del abad de St. Llorenç del Munt la «baiuliam mayorem ... de Mata de Pera». El laudemium se cobraba cuando el cargo había sido heredado. De hecho, en más de algún caso resulta difícil separar los pagos por uno y otro concepto; así, cuando en 1228 el abad de Sta. Maria de Roses cedió la baiulia de Roses y recibió «pro accapite et laudemio baiulie $\mathrm{L}$ aureos bonos novos et anfusinos»; $c f$. CSMR, 94.

${ }^{52} C P B A, 689$ (1239). En ocasiones esta fidelidad genérica se dobló de exigencias más específicas. Por una convencio establecida «laude et consilio proborum hominum» el baiulus Nadal de Mazanis y su hijo prometieron al monasterio de St. Cugat «ut nos non hospitemus ullum militem nec dominam in manso quem tenemus per $\mathrm{Scm}$. Cucuphatem et honori ipsius atque hominibus et quod nos non teneamus baiuliam militis nec domine sine vestro consilio et licenciam»; ACA/OR, Perg. St. Cugat del Vallès, 608 (1181).

${ }^{53} C P B A, 1108$ (1241); MASMM, Perg. Marfâ, 1 (1182); ACA/OR, Perg. St. Pere de Rodas, $18(1301)$

${ }^{54} \mathrm{DB}, 431$ (1293).

${ }^{55}$ ACA/OR, Rotllos St. Miquel de Cruilles, 15/1 (1243).

${ }^{56}$ ACA/OR, Perg. St. Llorenç del Munt, 856.

${ }^{57}$ AHG, Notarials Amer, Reg. 5, fols. 124-124 v.

${ }^{58}$ MASMM, Perg. Marfâ, 1 (1182). 
eventual señor anterior ${ }^{59}$. Se imponía además al baiulus la obligación de residir en el lugar donde ejerce su cargo: así, el prior maior et sacrista de St. Cugat llegó a exigir en 1286 que los baiuli de Valldoreix «debebant residere et facere staticam et continuam residenciam in domibus seu turri quas habent in villa de Valdaurex» y que debían ser «semper habitantes et affocati dicti monasterii sueque sacristie mayoris» ${ }^{60}$. Desde el siglo XIII el estatus de solidus y proprius homo pudo, en ocasiones, convertirse en un requisito indispensable para ejercer de baiulus. El año $1246 \mathrm{el} \mathrm{abad} \mathrm{de} \mathrm{St.} \mathrm{Llorenç} \mathrm{del}$ Munt encomendó a Guillema de Ameniis, en vida, la «baiuliam mayorem nostram de Mata de Pera», con la finalidad que «congreguetis ipsos fructus et redditus». Pero, también le exigió a Guillema que su marido Ramon «non congreget nec levet nec tangat aliquid parvum vel multum in ipsis fructibus et reditibus», y que «ille homo qui pro te levabit dictam baiuliam sit de nostris propriis hominibus de Mata de Pera ${ }^{61}$. La recaudación de los derechos del monasterio no se confiaba, pues, a nadie que no fuera 'hombre propio' de la abadía.

El señor podía disponer libremente de su baiulia y podía destituir el baiulus que no cumplía con su cometido, recuperar el cargo y encomendarlo

${ }^{59}$ CSMR, 94 (1228): el abad de Sta. Maria de Roses concede a Bernat de Ordeis y a su hijo la «baiuliam tocius nostri honoris parrochie Sce. Marie de Rodis et tocius ville nostre que est iuxta monasterium», y les exige «quod facitis vos homines proprios et solidos nostros et Sce. Marie». Además les impone que «si autem aliquis dominus apparuerit qui velit vel possit extraere vos de dominio nostro, quod redimatis ab illius dominio, ita ut in pace vos possidemus sicut solidos et proprios homines. Quod si facere nolueritis vel non potueritis, predictum donum baiulie sit irritum et vanum et ullam vobis optineat firmitatem». Bernat junto a su hijo «facio me et ipsum Bernardum, filium meum, homines proprios et solidos vestri et vestrorum successorum ... promittendo vobis et successoribus vestris et omni conventui Sce. Marie presenti et futuro per me et successores quod sim vobis fidelis et obediens sicut fidelis baiulus debet esse dominis suis». $C f$. además ACA/OR, Rotllos St. Miquel de Cruilles, 15/1 (1243); AHG, Notarials Amer, Reg. 7, fol. 20 (1292). El vínculo podía expresarse también en términos más bondadosos: en 1241 el baiulus Pere Clara se entregaba al monasterio de Amer y los monjes lo recibían «in fratrem et socium» al tiempo que le prometían «in domo nostra partem et societatem tam in temporalibus quam in spiritualibus» y le asignaban «victum et vestitum in honore nostro»; DSMA, 107.

${ }^{60} \mathrm{ACA} / \mathrm{OR}$, Perg. St. Cugat del Vallès, 1727.

${ }^{61} \mathrm{ACA} / \mathrm{OR}$, Perg. St. Llorenç del Munt, 408 (d). El vínculo personal establecido con el señor implicó restricciones a la hora de contraer matrimonio y elegir el cónyuge. Ya el 1226 el abad de St. Llorenç del Munt había establecido que la baiulia de Matadepera volvería a su poder si el baiulus no contraía matrimonio. Al mismo tiempo, pero, el abad dejaba claro que «si aliqua hora extra parrochiam de Mata de Pera uxorem duceris ... baiuliam statim nobis deliberetis»; ACA/OR, Perg. St. Llorenç del Munt, 408 (a). 
libremente a un tercero ${ }^{62}$. Con todo, se observa muy temprano cómo el cargo era transmitido de forma hereditaria a un hijo, sobrino o yerno ${ }^{63}$. Esta transmisión puede expresarse incluso como voluntad señorial explícitamente declarada en el momento de realizar la cesión del cargo, aunque condicionada a la indivisibilidad del mismo ${ }^{64}$. El caso de familias que con el laudamentum señorial retenían el cargo de baiulus de manera hereditaria está documentado desde mediados del siglo XII y en 1238 un baiulus de Mataró recibió de su señor la «baiuliam integriter ... quod tu et antecessores tui diu tenuistis et habuistis per me et antecessores meos ${ }^{65}$. Esta transmisión hereditaria del cargo podía realizarse incluso por línea femenina. Así, no es raro hallar una mujer actuando como baiulissa. En algún caso debió tratarse de una hija que había heredado el cargo de su padre ${ }^{66}$. Pero también hubo casos en que la

${ }^{62}$ Para el nombramiento del baiulus y la duración del cargo $c f$. LALINDE ABADÍA, Jurisdicción, pp. 251-254. Las condiciones de recuperación del cargo se expresan en ACB, Perg. Pia Almoina, 4, 10, 20 (1252): los señores ceden la baiulia mediante una charta y reconocen «nos vero non possimus emparare nec auferre dictam baiuliam tibi vel tuis dum potueritis inde nobis facere directum in posse nostro. Verum si tu vel tui non poteritis vel volueritis inde tibi vel vestris facere directum in posse nostro, reddatis nobis statim vel nostris hoc presentis instrumento et deinda dicta baiulia sit nobis et nostris perpetuo penitus absoluta sine aliquo vestro vestrorumque retentu ad nostras voluntates perpetuo faciendas». Para la destitución de un baiulus $c f$. ACB, Lib. Ant., IV, 449 (1122): Pere Ramon y su hermano restituyen al obispo de Barcelona el «honorem de Moleto et baiuliam ... propter multa mala et iniurias quas ei ... et suis clericis fecimus». $D B$, 431 (1293): el abad de St. Esteve de Banyoles, como señor del castillo de Porqueres, destituye al baiulus Barceló por no actuar satisfactoriamente en la gestión de la baiulia del castillo. Ibid. 432 (1293): el día siguiente el baiulus Barceló promete al abad bajo pena de 500 sous de Barcelona «quod ego bene, fideliter, utiliter et legaliter pro posse meo colligam et requiram census et redditus castri de Porchariis que ego teneor colligere et requirere racione baiulie mee»; además promete «quod servem iusticiam inter homines baiulie mee quos ego debeo distringere pro posse meo et ad querimoniam extraneorum ipsos distringam sicut debuero, sic quod per culpam meam ad aliam curiam non apportebit eos habere recursum».

${ }^{63} \mathrm{ACA} / \mathrm{OR}$, Perg. St. Llorenç del Munt, 290 bis (1154): los monjes de St. Llorenç del Munt ceden a Pere Guerau y su esposa Maiasenda un honor en Sentmenat; además «comendamus et damus vobis ... ipsam baiuliam quod tu Petrus et pater tuus olim tenuistis et habuistis ... ad servicium et fidelitatem nostram». Para la baiulia como cargo heredado de los padres $c f$. CCM, 334 (1178); 351 (1186); 381 (1204); 382 (1204); ACA/OR, Perg. St. Pere de Rodas, 18 (1301). Sobre el tema $c f$. además L1. To FIGUERAS, El monestir de Santa Maria de Cervià i la pagesia: una anàlisi local del canvi feudal. Diplomatari segles X-XII, Barcelona, 1991, pp. 164-166, y Mas, p. 165 y n. 87.

${ }^{64}$ MASMM, Perg. Marfâ, 1 (1182): la baiulia «revertat infantibus ... vel propinquis»; CCM, 382 (1204): se cede la baiulia «tibi ... et tuis perpetuo uni scilicet post alterum»; CSMR 94 (1228): la baiulia la herederarían «filio tuo ... omnique posteritati tue in perpetuum»; ACA/OR, Perg. Montalegre, 498 (1269): se cede la baiulia «tibi ... et uni de filiis tuis qui sit noster proprius ... uni post alterium successive».

${ }^{65}$ MASMM, Perg. Marfâ, 8 (1238).

${ }^{66}$ En este sentido puede interpretarse ACA/OR, Perg. St. Llorenç del Munt, 408 (d) (1246). 
viuda de un baiulus ejerció como baiulissa, bien junto al heredero ${ }^{67}$, o bien hasta que el heredero de la baiulia hubiese alcanzado la mayoría de edad o la edad adecuada para ejercer el cargo ${ }^{68}$. Por otra parte, sabemos que la baiulia podía constituir la aportación matrimonial de una mujer a su prometido: en este caso el cargo lo debió ejercer el futuro marido, y de éste pasaría a los hijos del matrimonio ${ }^{69}$. No obstante, el señor podía, como hemos podido comprobar, condicionar la transferencia del cargo al marido en el caso que éste no hubiera contraído un vínculo de fidelidad con el señor.

En definitiva, la transmisión hereditaria de la baiulia se reconoció como un derecho atribuído al baiulus y su familia siempre que éstos respondieran satisfactoriamente a las expectativas del señor ${ }^{70}$. Esto no significó una patrimonialización del cargo. La transmisión de la baiulia a un heredero quedó siempre condicionada al laudamentum del señor y éste podía negarlo si tenía motivos para ello $^{71}$. Esta norma se halla expresada ya

${ }^{67} \mathrm{ACB}$, Perg. Div. 1.5, 376 (1198).

${ }^{68}$ ASPP, Perg. 91 (1163): las monjas de St. Pere de les Puelles conceden una baiulia a Guillem de Ripollet, después de la muerte de la baiulissa, viuda del anterior baiulus, Berenguer Isarn, avio del mencionado Guillem.

${ }^{69}$ ADG, Perg. Pia Almoina, Llambilles, 15 (1197): Pere de Cortsaví, sacristán de la catederal de Girona, dona a Bernat de Sta. Cecília, Ramona, «filiam Berengarii de Planis, baiuli mei, olim defuncti, in uxorem». Junto a ella le cede «totum mansum et honorem et baiuliam quem predictus Berengarius de Planis, baiulus meus, tenebat per me et per anteccessores meos tam in parrochia Sci. Christofori de Lambillis quam in omnibus aliis locis sicut melius resonat in instrumento ab antecessore meo sibi corroborato et dici vel intelligi potest ad tuam utilitatem et comodum». Todo ello se entregaba a Bernat «ut iamdicta omnia habeas et teneatis vos ambo simul dum vixeritis sicut decet virum et uxorum et ad obitum vestrum remaneat infantibus vestris ex vobis ambobus procreatis». De la misma manera una baiulia podía ser la aportación matrimonial que el marido y heredero del cargo hacía a su esposa, $c f . C C M, 262$ ([ante 1135]).

${ }^{70}$ Cf. CSCV, 1298 (1220): pleito entre el monasterio de St. Cugat y Saurina de Valldoreix «pro se et filiam Bernardi de Valle Daurexio, filii eiusdem Saurine, defuncti ... super baiulia quam Guillelmus, abbas Sci. Cucuphatis et conventus dederant et comendaverant dicte Saurine et filio suo Bernardo». El monasterio reclama «quod post obitum Bernardi de Valle Daurexio et Saurine debebat reverti dicta baiulia in dominium cenobii». Saurina, por su parte "dicebat quod hoc adverbium 'semper' quod insertum est in carta donationis quam dictus abbas fecit dicte Saurine et filio suo Bernardo comprehendebat quod perpetuo habere debeant dicta Saurina et filia Bernardi de Valle Daurexio et heres eius baiuliam prenotatam». La sentencia da razón a Saurina y establece que ésta «et filia Bernardi de Valle Daurexio et heredes eius debeant perpetuo habere baiuliam prenotatam".

${ }^{71}$ En 1176 Pere de Valle Sicca hubo de restituir a St. Cugat «illam baiuliam quam per vocem patris mei iniuste tenere volebam»; $C S C V, 1107$. Por un acuerdo pactado días después el abad del monasterio volvió a otorgar a Pere la «baiuliam nostram ad fidelitatem nostram dum nobis placuerit»; ibid., 1108. En 1122 Pere Ramon y su hermano hubieron de restituir al obispo de Barcelona el «honorem de Moleto et baiuliam» por las "multa mala et iniurias» que habían cometido contra sus señor; ACB, Lib. Ant., IV, 449. 
mediados del siglo XII en la más temprana versión de los Usatges de Barcelon $^{72}$. Dado el caso, pudo imponerse el pago de una indemnización al baiulus destituído por parte del señor ${ }^{73}$.

\section{LA RETRIBUCIÓN DEL BAIULUS}

El baiulus era retribuído por su señor ${ }^{74}$. El conjunto de esta retribución podía designarse como baiulium, baiulivium, balliu ${ }^{75}$. Sólo en los dominios del conde pudo este conjunto recibir el calificativo de fevum, empleándose el mismo con el sentido de «revocable administrative tenures», lo que, para Th. N. Bisson, manifiesta un esfuerzo por restaurar el «old administrative order» en el cual «fiefs were conceptually identified with the fiscal land from which they were assigned ${ }^{76}$. En cuanto a la composición concreta de esta retribución, se puede documentar que el baiulus recibía en régimen de enfitéusis (ad accapitum) un mas (o un conjunto de bienes asimilable $)^{77}$, que a menudo quedaba vinculado de manera permanente al ejercicio del cargo («baiuliam spectantem et pertinentem ad mansum») ${ }^{78}$. Por su predio el baiulus (al igual que cualquier otro tenetor) quedaba obligado a pagar censos y realizar servicios diversos.

Entre las retribuciones propiamente dichas se contaban una serie de ingresos percibidos sobre los tenentes del dominio. Los más característicos de

${ }^{72} \mathrm{~J}$. BASTARDAS..., Usatges de Barcelona. El codi a mitjan segle XII. Establiment del text llatí i edició de la versió catalana del manuscrit del segle XIII de l'Arxiu de la Corona de Aragó de Barcelona, Barcelona, 1984, art. 83: «baiulias vero nullus baiulus concedat heredibus suis sine consensu senioris».

${ }^{73}$ To FIgueras, Monestir, 164-165; ACA/OR, Perg. Sta. Maria de Cervià, 773 (1210).

${ }^{74}$ Para este tema $c f$. BrutaIls, Etude, 235-236; LALINDE ABADÍA, Jurisdicción, pp. 254-256.

${ }^{75}$ BrutaILS, Étude, pp. 153-154.

${ }^{76}$ Bisson, Accounts, 1, pp. 35-36; Bonnassie, Catalogne, 1, pp. 209-211.

${ }^{77} C D S G, 421$ (1093); MASMM, Perg. Marfâ, 1 (1182): Estefania y su maritus, Guillem de Turre, y el hijo de ambos, Guillem, ceden a Joan de Valle Maiori el «mansum quem Ferretus de Matha tenebat et habebat per nos in termino castri Matharonis, in parrochia Sce. Marie Civitatis Fracte»; Joan retendría el mas «cum tua uxore Ferraria, filia iamdicti Ferreti, salvo nostro iure»; junto al mas Joan recibía también «nostram baiuliam totius nostri honoris quem in iamdicto termino habemus ut habetis eam omni tempore per nos tu et tui ad nostrum servicium et sis inde noster fidelis baiulus».

${ }^{78}$ ACA/OR, Rotllos St. Miquel de Cruilles, 11/1 (1301). 
estos ingresos eran, por una parte, el braciaticum y, por otra, el retrodecimum. El retrodecimum (redecimum, fem. retrodecima $>$ cat. redelme), documentado desde la segunda mitad del siglo $\mathrm{XII}^{79}$, equivalía aproximadamente a una décima u onceava parte de los diversos réditos recaudados por el baiulus $^{80}$; en 1241, por ejemplo, el señor de la domus de Brumira, en el Vallès, autorizó a su baiulus a percibir «totum retrodecimum pro tuo labore, scilicet XI partem» ${ }^{81}$. El braciaticum (bracagge $>$ cat. braçatge), por su parte, representa una imposición que se difundió a partir de la primera mitad del siglo XI como asociada a la baiulia («braciaticum per baiuliam») ${ }^{82}$, y que parece haber representado en general una decimosexta parte de los más diversos réditos señoriales, aunque también se han señalado variaciones locales de esta tasa ${ }^{83}$.

Entre los derechos gravados racione braciatici y retrodecimi figuraban, entre otros, los censos, los agraria, los usaticos (redemptiones), los laudemios, las intratas ${ }^{84}$, aunque, de hecho, los mismos parecen poder gravar cualquier fuente de exacciones: por ejemplo, los molinos (retrodecima

${ }^{79}$ ACB, Perg. Div. 1.5, 376 (1198); ACA/P, Sentmenat, 16, P, 14 (1213); ACA/OR, Perg. St. Llorenç del Munt, 408 (a) (1226): «accipias inde de omnibus eximentis nostris ad morem parroechie ... medium redecimum»; CSMR, 94 (1228). Cf. también ACA/OR, Perg. St. Cugat del Vallès, 608 (1181): el baiulus se asegura la continuidad del retrodecimum para el caso que el dominus alienara la baiulia.

${ }^{80} \mathrm{Cf}$. ACA/OR, Fons St. Joan de Jerusalem, Armari 16, Plec 15/17/c (1193): el vizconde Ponç de Cabrera concede «totam baiuliam de toto meo honore quod habeo in parrochia Sci. Martini de Cassiano ... et tu et tui habeas tuam redecimam fideliter de omnibus meis expletis et eximentis et terciis et stabilimentis et de redempciones personarum et de chestis et de denariis censi et de foriscapis sicut alii baiuli de meo honori habent et etiam habeas et accipias omnes anseres et fogacas quas in dicto honore accipio per tuam baiuliam». Para el retrodecimum $c f$. LALINDE ABADÍA, Jurisdicción, 213-214.

${ }^{81} C P B A, 1108$ (1241). Cf. además ACA/C, Perg. Jaume I, 884 (1242): «leves (scil. baiulus) retrodecimum scilicet undecimam mensuram vel partem vel undecimum denarium vel aliud similiter ut de penis et caponibus et de omnibus aliis exitibus».

${ }^{82}$ CSCV, 814 (1111); ASA, 214 (1132); ACA/C, Perg. Ram. Ber. IV, 331 (1160); CSCV, 1084 (1172); ACB, Lib. Ant., III, 717 (1175); II, 718 (1177); DB, 199 (1198); ACA/OR, Perg. Sta. Maria de Cervià, 1563 (1275); ACA/C, Alfons I, 155 (1174)..

${ }^{83}$ Para el braciaticum y su difusión $c f$. GMLC, 290-291; RoDÓN BINUÉ, Lenguaje, pp. 45-46; BRUTAILS, Etude, p. 154; para su tasa $c f$. DE HINOJOSA, Regimen, pp. 175-176; M. GOLOBARDES, Els remences dins el quadre de la pagesia catalana fins el segle XV. Peralada, 1973, pp. 151-152; BONNASSIE, Catalogne, 2, p. 579; TO FIGUERAS, Mas, p. 165.

${ }^{84}$ MASMM, Perg. Marfà, 8 (1238); CDSDG, 197 (1246): «retrodecimam ... de omnium predictorum agrariorum panis et vini ... de omnium intratarum et exitarum et aliorum foriscapiorum». 
molendini $)^{85}$. Ambas formas de retribución, no tenían, por otra parte, por qué excluirse. Así, en 1190 Guillem y Agnès de Campsentelles concedieron a Arnau tanto el braciaticum como el redecimum por ejercer la «baiuliam ... dominium nostrarum rerum totius honoris nostri quem habemus et habere debemus in termino castri de Matarone» ${ }^{86}$.

La participación del baiulus en las sumas cobradas en concepto de intrata, tercium, foriscapium y laudemium con motivo de la cesión (institutiones) y alienación de los honores cuya gestión le había sido confiada está documentada desde el siglo XII ${ }^{87}$. A esta participación, establecida «pro laudamento et firmamentum baiuli» ${ }^{88}$, podían añadirse censos diversos a cobrar por el baiulus sobre las instalaciones (molendinos, fabricas) $\mathrm{y}^{89}$, notablemente, sobre las tenencias administradas. Según los breves condales de 1151, al baiulus de Palafrugell se le entregaban porcos y gallinas $^{90}$; y en Prats de Molló el baiulus recibía «de isarn quarter derétro et espátla» y «de unoquoque urso áncham» ${ }^{91}$. El abad del monasterio de Arles concedió a un baiulus en 1168 en los masos de su dominio de Costoja, en el Vallespir, toda una serie de censos: entre éstos, "pernam unam», un «sester current de civada», un «porc de trescol vel XX denarios Rossilionenses», de «palea I fex», cuatro «garbes de civada», tres «migers de segle» $\mathrm{y}$ «ad Pentecostem accapte de ovis et formaticis ... et ad sagionem I eminam vini $»^{92}$. A un baiulus del castillo de Mataró se le otorgaron en 1238, además del braciaticum, diversos otros réditos, como los «corba et templa porcina ... et cistella

\footnotetext{
${ }^{85}$ ADG, Perg. Mitra, 15, 63 (1173).

${ }^{86}$ ACB, Perg. Pia Almoina, 4, 101, 28 (b). Cf. además ACA/OR, Perg. Montalegre, 498 (1269); ACA/OR, Perg. St. Cugat del Vallès, 1456 (1270); ACA/OR, Rotllos St. Miquel de Cruilles, 19/2 (1290): "vos recipiatis ibi braciaticum de illis locis unde exire debet et de aliis locis retrodecimum et de omnibus stabilimentis et firmanciis et placitis sicut consuetum est».

${ }^{87}$ CSMR, 84 (1157); ACB, Lib. Ant., III, 69 (1157); ASA, 431 (1172); CPBA, 680 (1239); CDSDG, 197 (1246); ACA/OR, Rotllos St. Miquel de Cruilles, 19/2 (1290); 11/1 (1301).

${ }^{88} \mathrm{ACA} / \mathrm{OR}$, Rotllos St. Pere de Galligants, $26 / 4$ (1254).

${ }^{89} \mathrm{ACA} / \mathrm{OR}$, Rotllos St. Pere de Galligants, 50/13 (1293): el herrero de Sta. Eugènia de Ter entrega al «baiulus annuatim duos gladios et duos fausonos».

${ }^{90}$ Bisson, Accounts, 2, doc. 1, J.

${ }^{91}$ Bisson, Accounts, 2, doc. 1, L.

${ }^{92}$ AlART, Documents, p. 8.
} 
racemorum $»^{93}$. La cesión de agraria al baiulus también está documentada: en 1153, por ejemplo, el conde Ramon Berenguer IV exigió a la hora de ceder una pecia de terra en Vilamajor, que «donetis omni tempore de expletis ... de pane et vino de ipsas tenedones Vam partem ad mei baiuli ${ }^{94}$; un baiulus de St. Miquel de Cruilles percibía en 1189 «tascham et braciaticum de espletis terrarum et vinearum ${ }^{95}$.

Por último, la retribución del baiulus podía consistir en la participación en las exacciones asociadas al mandamentum y districtum: así, un baiulus del abad de Arles tenía derecho a percibir I iova y I iornal a segada ${ }^{96}$; lo mismo se constata para unos baiuli de los monasterios de St. Cugat y St. Pere de Galligants ${ }^{97}$. El capbreu condal de Caldes de Montbui menciona las «ioves quas accipit baiulus et tenet pro comite ${ }^{98}$. La participación en los placitos y en las redempciones hominum et mulierum se documenta en el siglo XIII"99. En 1239 se les reconoció a unos baiuli de Terrassa la facultad de retener el retrodecimum en los derechos de «intestiis, excorchiis, cucuguciis, homicidiis» ${ }^{100}$. La alberga fue uno de los derechos atribuídos en 1151 al baiulus real de Vilamajor en calidad de fevum ${ }^{101}$. En 1174 un mas de de St. Martí Sacosta había de proporcionar alberga al baiulus del señor ${ }^{102}$. En 1168 el abad de Arles concedió pro baiulia en un mas «I migeram de civada ad mensuram Petralate pro alberga» ${ }^{103}$; y a un baiulus del abad de St. Pere de

${ }^{93}$ MASMM, Perg. Marfà, 8.

${ }^{94} \mathrm{ACA} / \mathrm{C}$, Perg. Ram. Ber. IV, 256 (1153).

${ }^{95} \mathrm{ACA} / \mathrm{OR}$, Rotllos St. Miquel de Cruïlles, $13 / 9$.

${ }^{96}$ AlART, Documents, p. 8.

${ }^{97}$ ACA/OR, Rotllos St. Pere de Galligants, 47/3 (1240); ACA/OR, Perg St. Cugat del Vallès, 1475 (1271)

${ }^{98}$ Bisson, Accounts, 2, doc. 1, B (1151).

${ }^{99}$ ACA/OR, Perg St. Cugat del Vallès, 1465 (1270); AHG, Notarials Castelló d'Empúries, Reg. 3, VII idus februarii (1288); ACA/OR, Rotllos St. Miquel de Cruilles, 19/2 (1290); 11/1 (1301).

${ }^{100} C P B A, 680$ (1239). Cf. además Bisson, Accounts, 2, doc. 116 ([1204-1205]); ACA/C, Perg. Jaume I, 1186 (1250).

${ }^{101}$ Bisson, Accounts, 2, doc. 1, A. ap. 31 .

${ }^{102} \mathrm{~J}$. Rius, Cartes antigues de Sant Martí Sacosta, "Analecta Sacra Tarraconensia", 4 (1928),

${ }^{103}$ AlaRT, Documents, p. 8. 
Galligants se le atribuyó en 1228 en un mas de Vilablareix «albergam unam et alterius inter festum Natalis Domini et Carniprivium et unum prandium quando segetes levantur et unam pernam in tempore sementerii ${ }^{104}$.

No queda siempre claro si la participación del baiulus en estos ingresos del señor no se derivaba en realidad de la propia facultad de percibir el braciaticum y/o el redecimum. Nótese, sin embargo, que en algunas ocasiones la participación del baiulus en las tasas de mutación se justificaba como cobro realizado pro redecimo o propter braciaticum ${ }^{105}$. Más explícita es una charta del año 1238 por la cual un señor concedió a su agente «quod de omnibus fructibus, panis grossorum et minutorum, vini et censuum denariorum et caponum et aliarum rerum et stabilimentum ac vendicionum sive nupciarum vel etiam redempcionum habeas braciaticum» ${ }^{106}$.

Ejemplos concretos de lo que representaba la remuneración (y las correspondientes obligaciones) de un agente señorial los proporcionan una serie de fuentes procedentes de fondos eclesiásticos. Éstas muestran que dicha remuneración representaba un conjunto complejo de derechos a los que podían añadirse ocasionalmente algunos otros que no hemos considerado como típicos. Un acuerdo pactado en 1213 entre el abad de St. Cugat del Vallès y Bernat de Plegamans, el encargado de gestionar la baiulia de Plicamanibus, atribuía a éste una parte de las iovas exigidas por el abad de los hombres de Palau de Plegamans ${ }^{107}$. Además, Bernat recibía el decimum, los capones y el retrodecimum en unos masos a cambio de mantener en condiciones los recipientes donde se almacenaba el vino recaudado en el dominio ${ }^{108}$. Además, Bernat debía proporcionar durante la cosecha un asno para transportar las garbas de cereal; una parte de la manutención del asno y de su conductor

${ }^{104} \mathrm{ACA} / \mathrm{OR}$, Rotllos St. Pere de Galligants, 29/26.

${ }^{105}$ ACG, Llibre Gran de la Sagristia Major, fols. 86-86 v. (1210); CPBA, 680 (1239).

${ }^{106}$ MASMM, Perg. Marfâ, 8.

${ }^{107}$ ACA/P, Sentmenat, $16, \mathrm{P}, 14$ (1213): «concessit etiam idem abbas prefato Bernardo de Plicamanibus in ipsis hominibus de Plicamanibus ei qui eandem baiuliam post eum habebit duas iovas, unam per baiuliam et aliam ad laborandum ipsam dominicaturm Sci. Cucuphatis». E documento en cuestión está muy dañado, pero su contenido puede reconstruirse a partir del Speculo antic, fol. 128, conservado ibid., 16 bis, $\mathrm{P}, 15$.

${ }^{108}$ «Et in ipsis mansis de Sinfreu decimum inter de pane et de vino et ipsos caponos de recognitionibus et retrodecimum de vindemiis, ita ut ipse preparet omnia vexella prepositi ad opus vindemiarum sine suptibus prepositi.» 
(nuncius) correría a cargo de los monjes ${ }^{109}$. Al baiulus se le concedían sobre tres masos del dominio los agraria cobrados de las cosechas del trigo y además la mitad de los réditos en concepto de cuguciis, exorchiis, intestiis, homicidiis, incendio, trobis ${ }^{110}$. Sobre estos tres masos el abad retenía la questia que cobraba también sobre el resto de masos de Plegamans y además las traginas ${ }^{111}$. El abad retenía también los stabilimenta de los masos de Plegamans, salvando al baiulus el derecho de retrodecimum sobre las tasas de mutación (laudemium); sólo sobre los tres masos atribuídos a Bernat éste retendría los stabilimenta ${ }^{112}$. El abad y el baiulus se dividirían por partes iguales el ordeum, la cibaria y la alberga exigida a los masos de Plegamans $^{113}$. En 1228, por otra parte, el abad de Sta. Maria de Roses concedió a Bernat de Ordeis y al hijo de éste, Bernat, y a la descendencia de ambos, la baiulia de la parroquia y villa de Sta. Maria de Roses, tal como la había tenido anteriormente el baiulus Arnau. A Bernat y su hijo se les encomendó «ut levetis et custodiatis taschas nostri honoris fideliter». A cambio podrían recaudar «de quolibet modio cuiuscumque generis sit tres eminas pro baiulia redecimo et vestro iure et non amplius. Scilicet, in area nostra accipiatis pro baiulia unam eminam de quolibet modio cuiuscumque generis sit sementis et non amplius». Además, el abad estableció que «accipiatis victum in monasterio nostro sicut unus monachus et comedatis illum infra portas monasterii et non extra nec tenemur vobis dare victum monasterii extra» ${ }^{14}$. En el año 1293, por

\footnotetext{
${ }^{109}$ «Et in tempore mesium habeat ipse Bernardus asinum sufficientem et idoneum nuntium ad portandas et colligendas omnes achones (?) annonas ipsius baiulie. Et accipiat inde asinus cibariam mensurati. Et nuntius qui eum duxerit unam corteriam frumenti ad mensuram fori de Granollers».

$11{ }$ "Concessit etiam ipsum mansum de Prato et de Cabanela et de Figeres, salvo iure et censu et usatico Sci. Cucuphatis in omnibus, excepto quodam frumento quod ibi petere consuerat praepositus quod perpetuo dimisit abbas. De cucuciis vero et de exorchiis et de intestiis et de homicidiis et de incendio et trobis retinuit sibi abbas dimidam, alia dimida eidem Bernardo concessa».

${ }^{111}{ }$ In istis $<\mathrm{t}>$ antummodo tribus mansis, et quandocumque fecerit abbas questiam in aliis hominibus de Plicamanibus, donent dictus Bernardus et sui post se, questiam pro iamdictis mansis secundum qualitate et valorem eorum. Et faciant homines ibi habitantes traginum Sco. Cucuphati sicut alii homines ipsius baiulie.»

${ }^{112}$ «Retinuit sibi abbas omnia placita et institutiones in omnibus mansibus de Plicamanibus et in omnibus salvo retrodecimo, preter in illis tribus mansis quos superius nominavimus in quibus concessum fuit eidem Bernardo facere stabilimenta cum consensu Sci. Cucuphatis».

${ }^{113}$ «Ipsum ordeneum et cibariam et albergas que idem Bernardus consueverat accipere in ipsis mansis de Plicamanibus habeant per medium abbas et Bernardus de Plicamanibus.»

${ }^{114}$ CSMR, 94.
} 
otra parte, el camarero del monasterio de Amer otorgó a Arnau de Casellis la baiulia de las parroquias de St. Julià de Cabrera, Sta. Maria de Corcó y St. Andreu de Pruit, prometiéndole la «retrodecima de blado tascarum» $\mathrm{y}$ «totum legumen et milium et comestiones sicut est consuetum ibi recipere baiulus»; a lo que añadía «de aventuris II denarios de quolibet solido et in manso de Planis unum velum unius arietis et in IIII mansis de Alodio in quolibet unam gallinam et unum casum ... et illum bladum et triticum et siliginem quod in predictis IIII mansis consuevit recipere baiulus ${ }^{115}$.

Otros ejemplos proceden de los dominios del obispo de Girona. De 1180 aproximadamente data una commemoratio seu caputbreve del baiulio que el baiulus de Domeny «accipit in honore Sancte Marie qui est domini episcopi» ${ }^{116}$. Unos años más tarde otra commemoratio fijó los ingresos a los que tenía derecho el baiulus (y el saio) episcopal de Ullà ${ }^{117}$. Precisamente para Ullà se han conservado dos documentos por los que se pacta la cesión de la baiulia y que se datan en 1186 y 1204, respectivamente. En ellos se fijan los ingresos a percibir por el baiulus, pero también lo que éste debía a su señor por la cesión de la baiulia ${ }^{118}$. Por la charta de 1204, en concreto, Arnau, el obispo de Girona, cedió a Guillem de Vinea Veteri la baiulia y la saionia de los honores de Sta. Maria d'Ullà y además una serie de ingresos: en primer lugar, «canabas et linos et legumina ortorum, porros et caules et omnes milcas et omnes squinas porcorum et ipsam vinogoliam et ipsos calamos et gallinas de trescols et ipsos omnes quartos de Torrocella»; en segundo lugar, el mas que habita Ponç Revengud y el mas que habita Guillem Isarn, como los había tenido anteriormente el suegro de Guillem; y además el mas de Berenguer Icardi. Más adelante se nos dice que del mas de Ponç Revengud el baiulus percibía «annuatim II solidos et I scinam porci et I gallinam pro trescol»; del mas que habita Guillem Isarn percibía, a su vez, «annuatim XII denarios et quartum et brachiaticum et mediam calcaturam». Todo ello se concedía a Guillem y a sus herederos a cambio de entregar por la baiulia «annuatim I albergam per quam debitis I porcum canonicalem et I eminam farine ad

\footnotetext{
${ }^{115}$ AHG, Notarials Amer, Reg. 7, fol. 20.

${ }^{116} C C M, 340$. Cabe indicar que la redacción de esta commemoratio fue precedida por un pleito entre el obispo y el baiulus por el «honorem quem hodie habes vel tenes per nos sicut melius pater tuus vel avuus tenuerunt per Gerundensem episcopum»; $c f . C C M, 334$ (1178).

${ }^{117} \mathrm{CCM}, 352$; el editor fecha el documento hacia 1186 .

${ }^{118} C C M, 351$ y 382.
} 
mensuram de Monellis et I sextarium vini sani et II paria caponum et II sextarios cibarie», además de «II saccos tortuosos et semper tercio anno I toallas que habeant $\mathrm{V}$ alnas in longitudine et VI palmos in latitudine», $\mathrm{y}$ finalmente también «singulis annis I porcum vel XII solidos barchinonenses». Por el mas que había sido de Gausfred Bernat el baiulus daría anualmente II solidos pro porco y de los expletos el quartum ${ }^{119}$.

Esta fijación literal y detallada de los ingresos vinculados al officium baiulie era a menudo el resultado de un acuerdo que ponía fin a una disputa judicial entre el señor y su agente. Éste es el caso del acuerdo, ya expuesto, que puso fin en 1213 al contencioso entre el abad de St. Cugat del Vallès y Bernat de Plegamans ${ }^{120}$. En 1168, el abad de Arles se vio obligado a establecer de manera exhaustiva la participación del baiulus en las exacciones sobre los masos del dominio de Costoja ${ }^{121}$. El monasterio de St. Daniel de Girona mantuvo en 1246 un pleito con uno de sus baiuli por la baiulia y los honores que el monasterio tenía en las parroquias de Vilafreser, Pujals, Santa Llogaia, Fellines y Viladasens; como acuerdo las monjas cedieron a su agente, "pro suo baiulivo in perpetuum» y en los honores y las possessiones mencionados, el retrodecimum tanto «de omnium predictorum agrariorum panis et vini» como «de omnium intratarum et exitarum et aliorum foriscapiorum que ratione dictarum possessionum et hominum predictorum inde exierint ${ }^{122}$. De 1278, por último, data otro acuerdo, por el cual el obispo de Girona y su baiulus de La Bisbal pactaban un reparto tanto de «iusticiis, exorquiis et placitis et aliis proventibus, exceptis poenis et bannis», como de «venditionibus, redemptionibus hominum et feminarum et in obligationibus et stabilimentis et alienationibus» ${ }^{123}$.

\footnotetext{
${ }^{119} \mathrm{CCM}, 382$.

${ }^{120} \mathrm{ACA} / \mathrm{P}$, Sentmenat, 16, P, 14 (1213) (16 bis, P, 15, fol. 128).

${ }^{121}$ ALART, Documents, p. 8.

${ }^{122}$ CDSDG, 197.

${ }^{123} \mathrm{ADG}$, Cartoral Rubricis Coloratis, 28 (1278).
} 


\section{EL ESTATUS DE LOS BAIULI}

Hasta mediados del siglo XII podemos suponer que los baiuli mencionados en nuestras fuentes eran individuos que, al margen de ejercer unas mismas funciones en el marco del dominio, compartían ciertas características socio-económicas y que se integraban en un estrato sociológico más o menos bien definido.

\subsection{El estatus socio-jurídico}

La procedencia social de los baiuli hay que buscarla entre aquellos campesinos acomodados, buenos conocedores de la sociedad y geografía locales, reclutados por los señores en un momento en el que se reorganizaron los dominios y se incrementaron tanto el número como el volumen de las imposiciones exigidas a los homines y feminas del señor. Junto a estos campesinos acomodados no es raro encontrar también herreros ffaber, ferrarius) ejerciendo como agentes del señor ${ }^{124}$. La opción señorial por uno $\mathrm{u}$ otro de estos personajes fue consciente, tanto como el rechazo a reclutar para la gestión del señorío a los milites ${ }^{125}$. El resultado de esta opción fue la configuración de un estrato de agentes que, surgido del campesinado, se convertía en pieza fundamental del dominio ejercido sobre el mismo. Con los años no pocos baiuli llegarían a acaparar notables fortunas participando en los beneficios regulares del dominio. Pero, más de uno debió buena parte de su bienestar a la apropiación y usurpación de los derechos pertenecientes a su señor y a las exacciones impuestas al margen de lo establecido por las costumbres $^{126}$. En cualquier caso, estos agentes pudieron consolidarse como

${ }^{124}$ Cf. CSCV, 1252 (1205); y J.C. SHIDELER, A Medieval Catalan Noble family. The Montcadas, 1000-1230, Berkeley, 1983, p. 38; ACA/P, Sentmenat, 16, P, 14 (1213) (16 bis, P, 15, Speculo antic, fol. 128).

${ }^{125} C f$. ACA/P, Sentmenat, 16, P, 14 (1213): el abad de St. Cugat cede la baiulia de Plegamans a Bernat de Plegamans, estableciendo, sin embargo, «qui vero post Bernardum iamdictam baiuliam habuerit non fiat miles. Et si fieret, amitat baiuliam et omnem beneficium et baiulie».

${ }^{126}$ Para pleitos en los que el señor acusa a su baiulus de no cumplir con sus obligaciones cf. CDSDG, 197 (1246); 240 (1255); ACA/OR, Perg. St. Cugat del Vallès, 1465 (1270); 1727 (1286); ACA/OR, Rotllos St. Pere de Galligants, 15/31 (1299). Para las exacciones impuestas al margen de las costumbres $c f$. ACA/P, Sentmenat, 16, P, 14 (1213); AMM/OR, Perg. Sta. 
estrato gracias a dichas fortunas y gracias a la sucesión de sus hijos, sobrinos o nietos en el cargo. Socialmente los baiuli representaron un estrato acomodado de la sociedad rural, entre una nobleza a la que quizas aspiraban pertenecer, por una parte, y un campesinado al que habían pertenecido sus antepasados, por otra ${ }^{127}$. A mediados del siglo XII los Usatges de Barcelona sancionaron este estatus del baiulus, situándolo en el límite sociológico que separaba al nobilis del rusticus ${ }^{128}$.

\subsection{Las distinciones}

El estatus que en lo jurídico y lo social era atribuído al baiulus a mediados del siglo XII experimentó hasta finales del siglo siguiente cambios profundos relacionados, sobre todo, con una reorientación de la manera de gestionar los dominios. Esta reorientación y su consecuente incidencia en el estatus de los baiuli se observa, sobre todo y antes que en cualquier otro lugar, en los dominios del conde-rey.

El baiulus dependiente de un señor laico o eclesiástico y el baiulus dependiente del soberano fueron figuras equiparables hasta mediados del siglo XII. Con J. Lalinde cabe retener que el origen de los baiuli reales estuvo «en la defensa de los intereses patrimoniales del monarca» ${ }^{129}$. Estas funciones estrictamente administrativas las siguieron desempeñando durante todo el siglo XIII. Una muestra de la actividad cotidiana de los baiuli regis puede encontrarse en los registros notariales de Terrassa que se conservan para 1237-1242. Estos registros evidencian cómo los baiuli regis de Terrassa

Maria de Cervià, 3 (1220) (To FIGUERAS, Monestir, pp. 164-165); ADG, Perg. Mitra, 20, 22 (1259); ADG, Cartoral Rubricis Coloratis, 28 (1278). Las querimonias dirigidas por eclesiásticos y campesinos contra un baiulus demuestran, sin genero de dudas, la existencia de estas agresiones. Aunque, cabe admitir, que en la mayoría de los casos las exacciones denunciadas en las querimonias eran realizadas con el consentimiento o incluso bajo la dirección del señor; $c f$., por ejemplo, ACB, Lib. Ant., III, 45 y 46 (ambos sin fecha); V. FARÍAs ZURITA, Una querimonia desconeguda procedent de l'antic arxiu de Sant Cugat del Vallès (ca. 1160-1162), "Gausac", 5 (1994), pp. 99-102.

${ }^{127} \mathrm{~J}$. VILAGINÉS, Berenguer de Bannalocha, batlle episcopal de Mollet, "Mollet del Vallès. Notes", 3 (1989), pp. 9-17.

${ }^{128}$ Bastardas, Usatges, art. 10; BonNASSIE, Catalogne, 2, p. 808. En los Usatges se establece una distinción entre, por una parte, el baiulus que «nobilis est et panem frumenti cotidie comedit et equitat", asimilado al miles, y, por otra, el ignobilis baiulus. Para una interpretación posible de este artículo $c f$. SHIDELER, Family, pp. 172-173. $137-143$

${ }^{129}$ LALINDE ABADÍA, Jurisdicción, p. 137; para el baiulus regis como gestor $c f$. ibid., pp. 
confirmaban las transacciones y transmisiones realizadas sobre los bienes del rey en Terrassa ${ }^{130}$. Por ello recibían el laudemium y su participación en los derechos de mutación, tal como se hace constatar en los instrumenta confirmatorios $^{131}$. Los mismos registros nos muestran cómo los baiuli regis realizaban las cesiones de bienes del fisco ${ }^{132}$; cómo realizaban los arrendamientos de ciertos derechos fiscales ${ }^{133}$; y cómo llevaban las cuentas de la fabrica («computum de omni illo locedo de fabrica») ${ }^{134}$. Por último, se han conservado en los citados registros las diversas causas judiciales tramitadas por los baiuli regis, relativas tanto a los homines y feminas del monarca como a otros individuos (los arrendatarios de impuestos, por ejemplo) ${ }^{135}$.

Sin embargo, ya a partir de la segunda mitad del siglo XII pueden observarse elementos de diferenciación entre la figura del baiulus regis y la del baiulus dependiente de otro señor ${ }^{136}$. Esta diferenciación fue, sobre todo, el producto de dos tendencias complementarias: por una parte, la 'racionalización' de la explotación y gestión de los dominios y, por otra, la implicación de los baiuli regis en la edificación del aparato estatal monárquico (específicamente en los aspectos fiscales y judiciales).

El paso de una baiulia cuyo ámbito geográfico de actuación era inpreciso a una baiulia territorialmente definida es un hecho que se observa por primera vez en los dominios del soberano. Esta territorialidad, sólo esbozada a mediados del XII, se había consolidado hacia $1200^{137}$. Así, en las tierras del Vallès, la baiulia de Terracia, la baiulia de Calidis y la baiulia de Villa Maioris (que incluía los fiscos de Carotitulo) se presentaron, desde

${ }^{130} \mathrm{CPBA}, 84$ (1237); 108 (1237); 209 (1237); 210 (1237); 212 (1237); 213 (1237); 236 (1237); 376 (1238); 1160 (1241); 115 (1237).

${ }^{131} C P B A, 99$ (1237) ; 175 (1237); 351 (1238).

${ }^{132} C P B A, 4$ (1237); 5 (1237); 6 (1237); 7 (1237); 184 (1237); 523 (1239); 823 (1239).

${ }^{133} C P B A, 8$ (1237); 9 (1237); 10 (1237); 11 (1237); 12 (1237); 13 (1237).

${ }^{134} C P B A, 154$ (1237).

${ }^{135}$ Para 1237 cf. CPBA, 2, 74; 75; 76; 81; 94; 102; 126; 127; 170; 211; 215; 224; para 1238 cf. $C P B A, 370 ; 416 ; 454 ; 463 ; 497$; para 1239 cf. $C P B A, 498 ; 587 ; 611 ; 666 ; 756 ; 760 ; 762$; 784; 804; para 1240 cf. $C P B A, 953$; 1048 ; para 1241 cf. $C P B A$, 1170; para 1242 cf. $C P B A$ $1325 ; 1326 ; 1328$. Las causas tramitadas son diversas: «ratione rixe», «ratione scugucie», «ratione vulneris et gladii tractis", "ratione illius camini quem condam mutaveratis", "ratione destruccionis mansi et honoris domini regis»... Se constata la falta de causas mayores.

${ }^{136}$ LALINDE ABADÍA, Jurisdicción, pp. 237-244.

${ }^{137}$ Bisson, Accounts, 1, p. 69. 
entonces, como distritos bien definidos que abarcaban los tres grandes conjuntos fiscales de la comarca, encomendados cada uno a uno o varios baiuli regis. Esta creación de distritos administrativos refleja la aspiración a gestionar de manera más eficaz los derechos fiscales. Esta misma aspiración impulsó también otras reformas de la gestión fiscal emprendidas por Ramon Berenguer IV y Alfons I. Estas reformas, determinadas básicamente por las necesidades y aspiraciones políticas de la monarquía, han sido estudiadas en profundidad por Th. N. Bisson, lo que nos dispensa de extendernos en ellas ${ }^{138}$. Retengamos, sólo, que desde la segunda mitad del reinado de Alfons I se inició una política de estrecho control de los agentes locales ${ }^{139}$. Del baiulus regis se esperaba que fuese una persona de ciertos requisitos, que asumía sus tareas tras prestar un juramento ${ }^{140}$. El cargo mismo pasó a concederse para un número limitado de años ${ }^{141}$. Se estableció, por otra parte, una bureaucratic supervision (Th. N. Bisson) sobre la actividad de los baiuli regis, dirigida sobre todo a un control periódico de las cuentas que se complementó con una administración central de la contabilidad ${ }^{142}$.

Junto a estos cambios que afectaban sus tareas fiscales y financieras se observa también una progresiva definición de las facultades judiciales que el baiulus regis había de ejercer en nombre del soberano a nivel local ${ }^{143}$. Por una parte, el baiulus fue confirmado como responsable de la administración de justicia local. Por otra parte, sin embargo, y como tal el baiulus pasó a integrarse en una jerarquía de la administración judicial que implantó una cierta subordinación de los baiuli locales a los agentes reales (baiulus, vicarius) de Barcelona, pasando éstos a reservarse ciertos delitos y a

\footnotetext{
${ }^{138}$ Bisson, Accounts; $1 ; c f$. además J. M. SALRACH, Estudio de los honores, censos, usos y dominios de la casa de Barcelona, "Estudios sobre renta, fiscalidad y finanzas en la Cataluña bajomedieval", ed. M. SÁNCHEZ MARTínEZ, Barcelona, 1993, pp. 29-70; M. SÁNCHEZ MARTÍNEZ, El naixement de la fiscalitat d'Estat a Catalunya (segles XII-XIV), Vic/Girona, 1995, pp. 29-38.

${ }^{139}$ Bisson, Accounts, 1, pp. 78-116.

${ }^{140}$ LALINDE ABADÍA, Jurisdicción, pp. 191-205.

${ }^{141}$ A. ARAGó, La institución baiulus regis en Cataluña, en la época de Alfonso el Casto, "VII Congreso de Historia de la Corona de Aragón", Barcelona, 1962, 3, p. 139; LALINDE ABADíA, Jurisdicción, pp. 208-209.

${ }^{142}$ ARAGÓ, Institución, pp. 139-141.

${ }^{143}$ LALINDE ABADÍA, Jurisdicción, pp. 128-130.
} 
constituirse como instancia de apelación ${ }^{144}$. En 1264 Jaume I ordenaba que el baiulus de Vilamajor fuese el que dictase la primera sentencia para los pleitos llevados ante la curia local, reservando, por otra parte, las apelaciones y los homicidios al baiulus de Barcelona; unas disposciones similares fueron establecidas el mismo año para Cardedeu ${ }^{145}$. En 1241 Jaume I concedíó a los habitantes de Fontrubí que por sus pleitos sólo responderían ante el baiulus local, aunque las apelaciones corresponderíann al vicarius de Barcelona ${ }^{146}$.

La aspiración a mejorar la gestión de los dominios, a crear un cuerpo de agentes eficaces y a articular los niveles de la administración y delimitar sus respectivas atribuciones representan elementos de una política real cuyo éxito, sin embargo, estuvo siempre condicionado al estado de las finanzas públicas. Hasta finales del reinado de Alfons I las reformas habían podido ser llevadas adelante de manera paulatina ${ }^{147}$. Sin embargo, desde finales del reinado de Alfons I y durante el de Pere I y los primeros años del reinado de Jaume I, el recurso sistemático al crédito como expediente para cubrir un defícit crónico de los ingresos fiscales tuvo efectos importantes tanto sobre la manera de gestionar los dominios como sobre el reclutamiento de los agentes locales $^{148}$. La necesidad urgente de dinero líquido llevó al arrendamiento de la baiulia y los ingresos vinculadas a ella al mejor postor. El pago por adelantado de este arrendamiento constituía, de hecho, un préstamo que se aseguraba mediante la cesión real de toda una serie de derechos. Así, al mismo tiempo que el baiulus regis pasaba a ser un acreedor del rey, la concesión de la baiulia quedaba asimilada a una pignoratio.

Indiquemos, para finalizar, que el mismo recurso comenzó a ser también aplicado a partir del 1200 en los dominios de las grandes casas nobiliarias y que también en estos dominios se observa la aparición de un baiulus que ejercía simultáneamente como «lender, guarantor, or administrator» (J. Shideler). En 1239, por ejemplo, el vizconde Ramon Folc de Cardona

${ }^{144}$ LALINDE ABADÍA, Jurisdicción, pp. 130-137.

${ }^{145}$ ACA, C, Reg. 13, fol. 217 (LALINDE ABAdíA, Jurisdicción, p. 130).

${ }^{146} D J A, 332$.

${ }^{147}$ BISSON, Accounts, 1, pp. 78-116; SÁNCHEZ MARTÍNEZ, Naixement, pp. 29-38.

${ }^{148}$ Bisson, Accounts, 1, 117-150; Th. N. BISSON, Las finanzas del joven Jaime I, 1213-1228, "X Congreso de Historia de la Corona de Aragón", Zaragoza, 1980, pp. 161-208; SÁNCHEZ MARTÍNEZ, Naixement, pp. 38-48. 
vendió por 4.500 sous a Bertran de Casanova, Bernat Bric y Bernat de Santpedor, por un año «totam baiuliam cum baiulinio et omnes exitus, redditus et proventus de Terracia et de Minorisa ... ut melius et plenius aliqui emptores ipsam baiuliam habuerunt vel tenuerunt». La suma representaba el debitum contraído por el vizconde con los tres individuos citados ${ }^{149}$. También en el caso de los Montcada, la aparición de una nueva categoría de baiuli estaba motivada por las necesidades financieras, y éstas explican el paso de una gestión directa de los dominios hacia lo que J. Shideler describe como «a mixed system, by which the incomes of some districts were sold for cash to bailiffs or rent-farmers» ${ }^{150}$. En cuanto a los dominios monásticos, los registros notariales permiten constatar, para casos como St. Cugat del Vallès y Sta. Maria d'Amer, que el arrendamiento regular de al menos una parte de los redditos («omnes census, agraria, decimas et omnes alios redditus») por parte de los cargos y las dignidades de la comunidad era una práctica bien consolidada a finales del siglo XIII y comienzos del XIV ${ }^{151}$. En definitiva: al igual que en los dominios reales se constatan también en los dominios eclesiásticos y baroniales unos cambios en la gestión humana y material que parecen motivados en buena medida (aunque ésto es un tema que queda por estudiar) por el estado de las finanzas señoriales.

\section{RÉSUMÉ}

La réorganisation spatiale des grands domaines ruraux et l'établissement dumansus comme élément basique de l'appropriation seigneuriale caractérise l'histoire de la seigneurie foncière de la Catalogne du nord-est au XIF et XIII ${ }^{\mathrm{e}}$ siècle. Ces processus ont été acompagnés par la création d'une figure original d'un officiel, le baiulus. L'article a pour but d'etudier

${ }^{149} C P B A, 680$.

${ }^{150}$ SHIDELER, Family, pp. 173-176 y 184-192.

${ }^{151}$ Un ejemplo: el año 1302 el camarero Pere de Bonastre arrendaba a Feliu de Borrello «a proximo transacto festo Sce. Crucis mensis madii usque ad aliud primum venturum festum Sce. Crucis mensis madii, omnes census, agraria, decimas et omnes alios redditus et medietatem omnium laudimiorum sive esdevenimentorum, retenta mihi alia medietate ipsorum laudimiorum sive esdevenimentorum quos et que ego nomine camere dicti monasterii habeo et accipio et habere et accipere debeo in parrochiis Sci. Vincencii de Molleto et Sci. Cipriani de Cabannis et in aliis parrochiis et locis quibus baiulus meus de Molleto levare consevit»; ACA/OR, Notarials Sant Cugat del Vallès, Reg. 8, fol. 23 v. 
comment cet officiel exerçait ses devoirs, comment il a été rémunéré et quel était son statut social et politique.

\section{SUMMARY}

The spatial reorganization of the greater rural estates and the establishment of the mansus as basic element of appropriation characterises the history of lordships in 12th and 13th centuries north-eastern Catalonia. These processes were accompanied by the creation of an original kind of official, the baiulus, who represented the lord in his estates. This paper deals with questions such as how this official exercised his duties, how he was rewarded by the lord and what was his social and political status. 